\title{
Morphometric analysis of suprabasal cells in oral white lesions
}

\author{
A H M SHABANA, * N G EL-LABBAN, K W LEE, I R H KRAMER \\ From the Department of Pathology, Institute of Dental Surgery and Eastman Dental Hospital, London, and the \\ * Laboratoire-Odontologie, Université de Paris, France
}

SUMMARY Surgical specimens from the cheek mucosa of 73 patients with white lesions were studied to determine various morphometric parameters that would help differentiate between the various types of oral mucosal white lesions that carry a risk of malignant change. Four cell types were represented: traumatic keratosis, leucoplakia, candidal leucoplakia and lichen planus, in addition to a control group of normal mucosa. The shape and size of the epithelial cells in two cell compartments, parabasal and spinous, were investigated by an interactive image analysis system (IBAS-1). The results showed an increase in the cell size in the parabasal cell compartment of all the white lesions compared with the normal mucosa. In the spinous cell compartment there was an increase in the cell size in lichen planus and traumatic keratosis; leucoplakia and candidal leucoplakia showed a slight decrease in cell size compared with the normal mucosa.

Attempts to discriminate between the four groups of white lesions showed that these parameters can provide a high level of separation between lichen planus and the three other groups, but not between leucoplakia, candidal leucoplakia, and traumatic keratosis.

Oral squamous cell carcinoma accounts for most malignant lesions of the oral mucosa. ${ }^{1}$ The tumour may arise in a part of the mucosa that previously appeared to be normal, but it may also be preceded by clinically detectable lesions of the type known to predispose to malignancy. The most common of these lesions is leucoplakia which is defined as a white patch or plaque that can not be attributed to any other disease. $^{2}$ In general, the rate of malignant change in oral leucoplakia ranges between 3 and $6 \% .^{3}$ This rate may be higher in particular variants of leucoplakia such as candidal leucoplakia and speckled or nodular leucoplakia. Malignant change in candidal leucoplakia was reported to be as high as $30 \%$ and in speckled leucoplakia as high as $26 \% .{ }^{45}$ Most forms of oral lichen planus carry little or no risk of malignant transformation, though some observers believe that there may be a clinically imported risk in the atrophic or erosive form. The reported rate of malignant transformation in patients with oral lichen planus ranges between 0 and $2 \%{ }^{67}$

Mucosal lesions that may be precancerous pose problems for differential diagnosis, determining the risk of malignant change, and estimating how long it

Accepted for publication 6 October 1988 will take for such a change to occur. One of the most difficult differential diagnoses is that between leucoplakia and lichen planus, in particular those cases showing epithelial dysplasia with lichenoid features. ${ }^{8}$ An accurate diagnosis of these lesions is of great importance as misdiagnosis may have serious implications. The histopathological diagnosis of oral premalignant lesions is based on the subjective evaluation of morphological anomalies within the lesional tissue, but the wide variation between observers has been commented on by several authors, ${ }^{9-11}$ and there is a constant search for more objective means of evaluation.

In the assessment of dysplastic and neoplastic lesions great emphasis is placed on the changes in nuclear and cellular size and shape. To overcome the unreliability in the subjective approach use may be made of computer-based image analysis techniques.

The aim of the present study was to investigate the value of certain shape and size-measuring parameters in discriminating between different types of oral mucosal white lesions.

In a previous paper ${ }^{12}$ we analysed the basal cell layer in the epithelium of oral white lesions and squamous cell carcinoma by the interactive image analysis system IBAS-1. We found an increase in the size of the cell and the nucleus in the lesions with high risk of malignant 
change and in carcinoma. In the present study, we analysed the parabasal and spinous cell layers (compartments) for the cell shape and size.

\section{Material and methods}

A retrospective study was made of 73 specimens taken from the buccal mucosa of 73 patients. The specimens were selected from the records in the department of pathology at this hospital. These comprised 29 leucoplakias (including nine candidal leucoplakias), 20 specimens of lichen planus, 14 of traumatic keratosis and 10 specimens of normal mucosa obtained during minor oral surgery. The lesions were diagnosed by two of the authors (KWL and AHMS) using the criteria recommended by the World Health Organization. ${ }^{2}$ Candidal leucoplakia was diagnosed according to the criteria of Cawson and Binnie. ${ }^{4}$ Clinically, the cases of lichen planus were reticular in nine, plaque in four, atrophic in three and of a mixed pattern in four. The histological diagnosis of lichen planus was made by finding at least four of the following features including (vi) and the absence of keratin plugging: (i) parakeratinised epithelium or orthokeratinised epithelium; (ii) saw tooth appearance of the rete processes; (iii) the presence of a granular cell layer; (iv) liquefaction degeneration of the basal cells; (v) "civatte" or "colloid" bodies in the epithelium; and (vi) diffuse inflammatory cell infiltration confined to the superficial part of the lamina propria, with the infiltrate consisting mainly of lymphocytes except in the vicinity of an ulcer or erosion.

The age and sex of the patients are presented in table 1.

\section{MORPHOMETRIC TECHNIQUE}

The technique was previously described by Shabana. ${ }^{13}$ Briefly, the cells were measured by a semiautomatic image analysis system (IBAS-1, Kontron) in $5 \mu \mathrm{m}$ thick paraffin wax sections stained with haematoxylin and eosin. The system comprises a microcomputer, a digitiser tablet, a drawing pen (stylus), a video camera (CCTV, Hitachi) attached to a light microscope (Olympus, BH-2) and a dot matrix printer (OKI, DP-125). The measurements were made by tracing the contour of the cells displayed on a black and white

Table 1 Age and sex of patients studied

\begin{tabular}{|c|c|c|c|c|c|}
\hline & \multirow{2}{*}{$\begin{array}{l}\text { No of } \\
\text { patients }\end{array}$} & \multicolumn{2}{|l|}{ Age } & \multicolumn{2}{|c|}{ Sex } \\
\hline & & Range & Mean & $M$ & $F$ \\
\hline $\begin{array}{l}\text { Normal mucosa } \\
\text { Traumatic keratosis } \\
\text { Leucoplakia } \\
\text { Candidal leucoplakia } \\
\text { Lichen planus }\end{array}$ & $\begin{array}{r}10 \\
14 \\
20 \\
9 \\
20\end{array}$ & $\begin{array}{l}40-67 \\
36-73 \\
33-75 \\
31-80 \\
30-78\end{array}$ & $\begin{array}{l}(49 \cdot 6) \\
(50 \cdot 7) \\
(52 \cdot 4) \\
(53 \cdot 4) \\
(51 \cdot 8)\end{array}$ & $\begin{array}{r}5 \\
6 \\
10 \\
6 \\
10\end{array}$ & $\begin{array}{r}5 \\
8 \\
10 \\
3 \\
10\end{array}$ \\
\hline
\end{tabular}

monitor, the contrast of the image being improved by a green substage filter. A $\times 100$ oil immersion objective was used to provide the largest possible image to minimise human error in tracing. The final magnification was 2000 at the monitor.

For each specimen one or more representative sections were selected. In the lesional tissues normal looking areas were masked by using a black ink marker. Keratinocytes were then measured in two cell compartments. These were (i) parabasal which is defined as a two-cell thick layer superficial to the basal cell layer, and (ii) spinous which is defined as multicell layer extending superficially from the parabasal compartment to the granular cell layer in the keratinised epithelia or to the surface in non-keratinised epithelia.

Identifiable non-keratinocytes such as dentritic cells and inflammatory cells, as well as degenerate cells, and those undergoing mitosis, were not measured.

\section{MORPHOMETRIC PARAMETERS}

The size of the cell was represented by area, perimeter, and maximum diameter (Dmax). The shape was represented by form factor (PE) and contour index (CI). PE assesses the deviation from circularity by the relation:

$$
4 \times \frac{22}{7} \times \frac{\text { cell area }}{\text { cell perimeter }}{ }^{2}
$$

By this formula a circle has a value of 1 and an ellipse or an irregular structure is less than 1 .

"CI" measures the regularity of the particle outline ${ }^{14}$ by the formula:

$$
\frac{\text { cell perimeter }}{\sqrt{\text { cell area }}}
$$

A value of 3.54 is obtained from a circle. Higher values are obtained with the increase in the indentation or convolutions of the outline.

The number of the cells to be measured from each cell compartment was determined by the cumulative mean plot. ${ }^{15}$ The nearest eight cells to the centre of the monitor were measured (to avoid possible image distortion at the edges of the monitor). The process was repeated in 25 fields selected by moving the microscopic stage to the side while the section was out of focus (to avoid selectivity in sampling). Several sections were used where the length of the epithelium was less than $5 \mathrm{~mm}$. Using this method, 120 cells obtained from 15 fields were found to provide a representative sample for the various parameters. The results were then represented by the mean and the standard deviation. No corrections were applied for section thickness or the Holmes effect, ${ }^{16}$ so that the measurements represent the morphometric image as seen.

The Kruskal-Wallis test was used for comparing the 
differences between several group distributions. The difference between two group distributions was compared by the Mann-Whitney U test. These rank sum tests were used as the data were often asymmetrical. ${ }^{17}$ A level of $5 \%$ was accepted as an indicator for significant difference between groups. The difference between group means divided by the pooled standard deviation is given the value (d). ${ }^{18}$ The variables with high (d) values discriminate best between groups.

\section{Results}

The results of measuring the keratinocytes in the parabasal and the spinous cell compartments are presented in table 2. Candidal leucoplakia is presented separately from leucoplakia; it was seen as a more homogeneous group as indicated by small standard deviations. The Kruskal-Wallis test showed significant differences between the five groups in the two cell compartments. This test, however, does not show the differences between group pairs and it is not possible to know which group or groups are responsible for the differences. The Mann-Whitney $U$ test was used for this type of comparison when necessary.

Table 2 shows that, compared with the normal mucosa, the cell size in the parabasal cell compartment was increased in all of the pathological groups. In the spinous cell compartment leucoplakia and candidal leucoplakia showed a smaller cell size than that in the normal mucosa, whereas traumatic keratosis and lichen planus had larger cell sizes. There was a significant decrease in cell area and perimeter in the spinous cells of candidal leukoplakia $(p<0.05$ and $\mathrm{p}<0.001$, respectively). The increase in the cell size of lichen planus was highly significant $(p<0.001$ for all the parameters).

PE and CI showed few differences between groups in the parabasal cell compartment except for lichen planus. The decrease in form PE was significant compared with that in the normal mucosa $(\mathrm{p}<0.05)$, traumatic keratosis $(p<0.01)$, leucoplakia $(p<0.01)$ and candidal leucoplakia $(p<0.01)$. In the spinous cell compartment only lichen planus had a lower value for factor PE than that in the normal mucosa. All the other groups had higher values than in the normal mucosa. Lichen planus was not significantly different from normal mucosa but was different from all the other groups ( $p<0.001$ for each group).

The contour index seemed to have a similar pattern to the factor PE. In the parabasal cell compartment CI was highest in lichen planus indicating a pronounced increase in cell indentation and convolutions. In the three other groups of white lesions CI was lower than in the normal mucosa with the lowest value in the group of traumatic keratosis. Lichen planus was significantly different from the normal mucosa $(p<0.01)$ and from all the other groups of white lesions ( $p<0.001$ for each). In the spinous cell compartment the most regular contour was in candidal leucoplakia and the least regular was in lichen planus. Leucoplakia and traumatic keratosis had values slightly lower than those for normal mucosa. Significant differences were obtained when lichen planus was compared with the normal mucosa $(p<0.01)$ and with all the groups of white lesions ( $p<0.001$ for each).

From the above results and by comparing the individual groups, it seemed that the enlargement of the cells in lichen planus and their deviation from circularity were responsible for the significant differences between groups. It was, therefore, of interest to find the parameters which best discriminate lichen planus from the rest of the white lesions. The (d) value was calculated to give an indication for the magnitude of separation between lichen planus and the three other groups, leucoplakia, candidal leucoplakia, and traumatic keratosis. Table 3 shows the parameters which had (d) of $>1.2$ and were thus

Table 2 Size and shape of parabasal and spinous cells of the different diagnostic groups (Mean (SD))

\begin{tabular}{|c|c|c|c|c|c|c|}
\hline Parameter & Normal & $\begin{array}{l}\text { Traumatic } \\
\text { keratosis }\end{array}$ & Leucoplakia & $\begin{array}{l}\text { Candidal } \\
\text { leucoplakia }\end{array}$ & Lichen planus & p Value \\
\hline $\begin{array}{l}\text { Parabasal: } \\
\text { Area } \\
\text { Perimeter } \\
\text { Dmax } \\
\text { PE } \\
\text { CI }\end{array}$ & $\begin{array}{cc}70.26 & (12.97) \\
35.75 & (3.91) \\
12.45 & (1.57) \\
0.700 & (0.041) \\
4.279 & (0.173)\end{array}$ & $\begin{array}{cc}83.46 & (16.43) \\
37.86 & (3.07) \\
13.49 & (0.88) \\
0.682 & (0.074) \\
4.184 & (0.326)\end{array}$ & $\begin{array}{cl}89.42 & (17.34) \\
40.24 & (5.09) \\
14.01 & (1.75) \\
0.689 & (0.061) \\
4.267 & (0.206)\end{array}$ & $\begin{array}{cc}89.52 & (11.22) \\
39.92 & (2.59) \\
14.06 & (0.98) \\
0.698 & (0.024) \\
4.227 & (0.092)\end{array}$ & $\begin{array}{cc}112.51 & (16.00) \\
48.38 & (4.16) \\
17.00 & (1.68) \\
0.617 & (0.049) \\
4.573 & (0.236)\end{array}$ & $\begin{array}{l}0.001 \\
0.001 \\
0.001 \\
0.01 \\
0.05\end{array}$ \\
\hline $\begin{array}{l}\text { Spinous: } \\
\text { Area } \\
\text { Perimeter } \\
\text { Dmax } \\
\text { PE } \\
\text { CI }\end{array}$ & $\begin{array}{cl}187.85 & (27.70) \\
61.02 & (3.45) \\
20.01 & (2.31) \\
0.579 & (0.058) \\
4.478 & (0.278)\end{array}$ & $\begin{array}{cc}205.37 & (43.73) \\
62.99 & (7.30) \\
21.36 & (1.81) \\
0.633 & (0.092) \\
4.432 & (0.439)\end{array}$ & $\begin{array}{cl}178.03 & (33.84) \\
57.63 & (7.92) \\
19.32 & (2.76) \\
0.663 & (0.050) \\
4.344 & (0.225)\end{array}$ & $\begin{array}{cl}157.41 & (19.82) \\
53.79 & (2.76) \\
18.73 & (1.00) \\
0.663 & (0.039) \\
4.300 & (0.153)\end{array}$ & $\begin{array}{cl}227.97 & (33.84) \\
74.49 & (6.36) \\
27.36 & (3.63) \\
0.532 & (0.072) \\
4.958 & (0.416)\end{array}$ & $\begin{array}{l}0.001 \\
0.001 \\
0.001 \\
0.05 \\
0.05\end{array}$ \\
\hline
\end{tabular}

Units; $\mu \mathrm{m}^{2}$ for area and $\mu \mathrm{m}$ for perimeter and maximum diameter.

p Value; probability of no difference between groups using Kruskal-Wallis test. 
Table 3 (d) Distance for size and shape parameters

\begin{tabular}{|c|c|c|c|c|}
\hline Size parameters & (d) $p$ & & Shape parameters & (d) p value \\
\hline $\begin{array}{l}\text { Spinous cell Dmax } \\
\text { Spinous cell perimeter } \\
\text { Parabasal cell perimeter } \\
\text { Parabasal cell Dmax } \\
\text { Parabasal cell area }\end{array}$ & $\begin{array}{l}1.66 \\
1.53 \\
1.53 \\
1.52 \\
1.27\end{array}$ & $\mathrm{p}<0.001$ & $\begin{array}{l}\text { Spinous cell PE } \\
\text { Spinous cell CI } \\
\text { Parabasal cell CI }\end{array}$ & 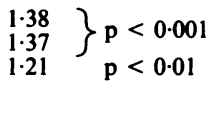 \\
\hline
\end{tabular}

$P=$ probability of no difference when comparing 20 lichen planus lesions with 43 leucoplakias and traumatic lesions.

more powerful in discrimination. These parameters in order were: spinous cell Dmax; spinous cell perimeter; parabasal cell perimeter; parabasal cell Dmax; spinous cell PE; spinous cell $\mathrm{CI}$; parabasal cell area; and parabasal CI. All these parameters were highly significant when lichen planus was compared with the pooled groups of other white lesions $(p<0.001)$. Fig 1 shows the individual values of the cases in the different diagnostic groups. When a maximum diameter of $23 \mu \mathrm{m}$ was regarded as a discriminating point, 18 of 20 lichen planus specimens $(90 \%)$ could be clearly separated from 49 of the 53 specimens in the other groups. The four specimens that were not separated from lichen planus were traumatic keratosis $(n=2)$, normal mucosa $(n=1)$, and leucoplakia $(n=1)$. It is interesting to note that none of the candidal leucoplakias had large cell diameters. Another example of the separation between lichen planus and the other groups of white lesions is given in fig 2 using the form factor $\mathrm{CI}$. The contour index in the spinous cell compartment could separate 17 of 20 lichen planus specimens (85\%) from 27 of 29 leuco- plakias and candidal leucoplakias $(93 \%)$ when a value of 4.6 was used as a discriminating point. Forty per cent of the normal mucosa and $36 \%$ of traumatic keratosis, however, had values greater than 4.6 for CI. Using several parameters for the discrimination was not useful as the coefficient of correlation was rather high between the variables (table 4).

\section{Discussion}

Our results show that the cell dimensions in the groups of white lesions were increased compared with those of the normal mucosa. This increase was found in the parabasal cell compartment in addition to selective increase in the spinous cell compartment. The latter was found in traumatic keratosis and in lichen planus. This is in contrast to our previous results from the basal cell compartment, ${ }^{12}$ where we found a gradual increase in cell size from the normal cheek mucosa through lesions believed not to predispose to cancer (traumatic keratosis) and lesions which might be premalignant (lichen planus) to lesions which are

$$
\Delta \Delta \Delta \Delta \Delta \Delta \Delta \Delta \Delta \Delta \Delta \Delta \Delta \Delta \quad \Delta \quad \Delta \quad \Delta \quad \Delta \quad \Delta
$$

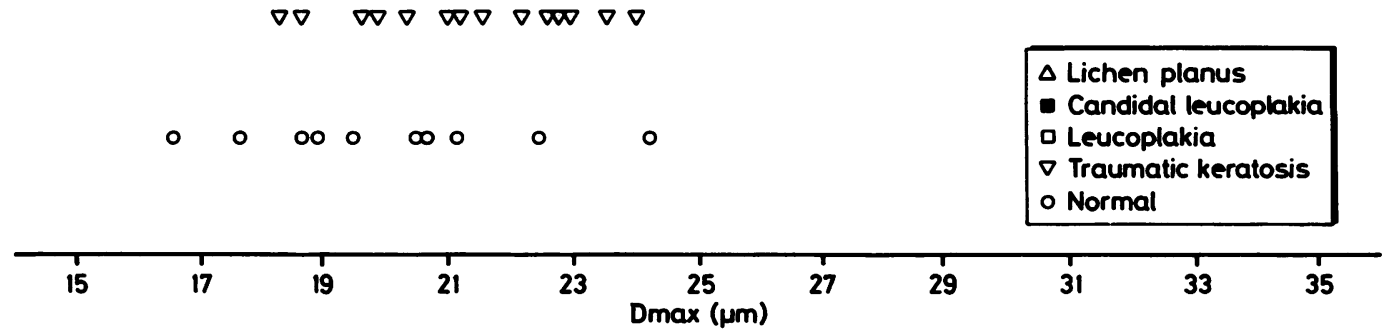

Fig 1 Spinous cell Dmax. In lichen planus only two specimens had values of less than $23 \mu m$; in leucoplakia ( $n=1)$, traumatic keratosis $(n=2)$, and normal mucosa $(n=1)$ diameters were greater than $23 \mu m$. 

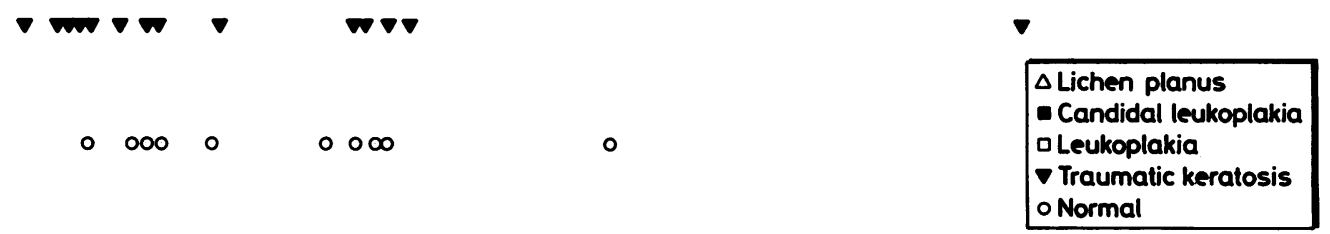

\begin{tabular}{|c|c|c|c|c|c|c|c|c|c|c|c|}
\hline 4.0 & 4.2 & 4.4 & 4.6 & 4.8 & 5.0 & 5.2 & 5.4 & 5.6 & 5.8 & 6.0 & 6.2 \\
\hline
\end{tabular}

Fig 2 Spinous cell (CI). In lichen planus three specimens had values of less than 4.6 for the index. None of the candidal leucoplakia group reached this value, but two exceeded $i$. While this parameter may be useful for differentiation between lichen planus and leucoplakias, there is a large proportion of traumatic keratosis which have values higher than $4 \cdot 6$, as is the case with normal mucosa.

generally believed to be premalignant (leucoplakia and candidal leucoplakia). On the contrary, the present results from the spinous cell compartment showed a decrease in the size of the cells in the lesions which are believed to be premalignant, leucoplakia and candidal leucoplakia showing a small cell size compared with the normal mucosa, and with a significant difference between candidal leucoplakia and normal mucosa ( $p<0.001$ for perimeter and $\mathrm{p}<0.05$ for area).

It was previously reported that in hamsters the cell size may increase following the application of turpentine $^{1920}$ and chemical carcinogens. ${ }^{21}$ This increase seems to be pronounced in the basal cell compartment rather than in the more superficial cell compartments. ${ }^{22}$ The superficial cell layers of the stratified squamous epithelium may increase in size by mechanical trauma such as repeated friction, ${ }^{23}$ during

Table 4 Correlation coefficient between eight best discriminators for lichen planus

\begin{tabular}{llllllll}
\hline Parameters & 2 & 3 & 4 & 5 & 6 & 7 & 8 \\
\hline 1 Spinous cell Dmax & 0.94 & 0.71 & 0.78 & 0.80 & 0.79 & 0.54 & 0.65 \\
2 Spinous cell & & 0.67 & 0.69 & 0.74 & 0.72 & 0.52 & 0.61 \\
$\quad$ perimeter & 0.67 & 0.96 & 0.56 & 0.56 & 0.89 & 0.69 \\
3 Parabasal cell perimeter & & & 0.64 & 0.64 & 0.80 & 0.75 \\
4 Parabasal cell Dmax & & & & 0.96 & 0.27 & 0.78 \\
5 Spinous cell PE & & & & & 0.27 & 0.77 \\
6 Spinous cell CI & & & & & & 0.29 \\
7 Parabasal cell area & & & & & & - \\
8 Parabasal cell CI & & & & & & &
\end{tabular}

wound healing, ${ }^{2425}$ after removal of the stratum corneum by Scotch-tape stripping ${ }^{26}$ and following hair plucking. ${ }^{27}$ The changes in cell size during the menstrual cycle $^{28}$ and at different age groups ${ }^{29}$ have also been reported, although there were no significant differences. While mechanical trauma may have a role in the enlargement of the cells in traumatic keratosis, the significant enlargement of the cells in lichen planus remains to be explained.

During routine microscopic examination of oral lichen planus lesions, the spinous cells often appear flattened and elongated. It was interesting to find that the shape factors PE and CI were sensitive enough to provide numerical values which express these subjective descriptions. The present results showed that the spinous cells of lichen planus are significantly deviated from circularity in comparison with the other white lesions. The contour index showed a significant increase in indentation and convolutions. It was possible to separate 17 lichen planus lesions $(85 \%)$ from 27 leucoplakias and candidal leucoplakias $(93 \%)$ using the spinous cell contour index. The value of such separation should be considerable as the histological distinction between lichen planus and leucoplakia of the oral mucosa is often difficult, and serious implications may result from misdiagnosis, a problem commented on by several authors..$^{30-34}$

One of the critical reports ${ }^{35}$ challenging the concept of malignant transformation in oral lichen planus lesions stated that 207 of 223 cases reported to have 
undergone malignant change had insufficient data to support the initial diagnosis. In a recent paper ${ }^{8}$ Krutchkoff and Eisenberg set the following criteria for identifying microscopically the lichen planus and lichenoid lesions. The requisite features of lichen planus are: (i) liquefaction degeneration of basal cells; and (ii) band-like infiltrate of lymphocytes in the lamina propria that intimately intermingles with the basal cell region of the surface epithelium. Additional features of lichen planus, though not prerequisite to diagnosis are: (i) saw tooth rete pegs; (ii) hyperkeratosis or parakeratosis; (iii) separation of the surface epithelium from the underlying connective tissue with uneven plane of cleavage; and (iv) civatte bodies. Disqualifying features for the diagnosis of lichen planus are: (i) any or all of the features of epithelial dysplasia; and (ii) presence of substantial numbers of plasma cells, eosinophils, or neutrophils within the band-like infiltrate. The category lichenoid dysplasia includes cases showing features of lichen planus in addition to any two or more of the features of epithelial dysplasia. The cases for which it is difficult to establish a precise diagnosis were regarded as non-specific lichenoid stomatitis. The authors also recognised other specific entities-for example, discoid lupus erythematosus-which often share lichenoid features. This grouping aims essentially at restricting the possibility of diagnostic errors. In the present study the diagnosis of lichen planus cases was based on strict clinicopathological criteria. Accordingly, we consider the group of lichen planus to be at least fairly diagnosed, though we did not exclude cases showing features of epithelial dysplasia.

By using the values of $(d)$ it was possible to obtain an indication for the parameters which best discriminate lichen planus. The spinous Dmax had the highest value. Using this parameter it was possible to separate clearly between 18 lichen planus lesions $(90 \%)$ and 40 different other white lesions (93\%) (traumatic keratosis, leucoplakia, and candidal leucoplakia). The two cases of lichen planus which could not be separated were one erosive form and the other plaque form. Histologically the erosive lesion showed a moderate degree of epithelial dysplasia; accordingly, this might be regarded as lichenoid dysplasia. ${ }^{8}$

We conclude that the shape of the epithelial cell seems to be a promising morphometric feature, which has previously received little attention in the diagnosis of lichen planus. Finally, we believe that the use of spinous cell maximum diameter offers a valuable and objective criterion in the diagnosis of lichen planus, thus improving the differentiation of this condition from lesions carrying a greater risk of malignant change.

\section{References}

1 Binnie WH, Cawson RA, Hill GB, Soaper AE. Oral cancer in
England and Wales. A national study of morbidity, mortality, curability and related factors. London, HMSO, 1972.

2 WHO. Collaborating centre for oral precancerous lesions. Definition of leukoplakia and related lesions. Oral Surg 1978;46: 518-38.

3 Pindborg JJ. Oral cancer and precancer. Bristol: J Wright, 1980.

4 Cawson RA, Binnie WH. Candidal leukoplakia and carcinoma: a possible relationship. In: Mackenzie IC, Dabelsteen E, Squier CA, eds. Oral premalignancy. Iowa: University of Iowa Press, 1980;59-66.

5 Banoczy J. Follow-up study in oral leukoplakia. J Maxillofac Surg 1977;5:69-75.

6 Murti PR, Daftary DK, Bhonsle RB, Gupta PC, Mehta FS, Pindborg JJ. Malignant potential of oral lichen planus: observation in 722 patients from India. J Oral Pathol 1986;15:71-7.

7 Silverman S Jr, Gorski M, Lozada-Nur F. A prospective follow-up study of 570 patients with oral lichen planus: persistence, remission and malignant association. Oral Surg 1985;60:30-4.

8 Krutchkoff DJ, Eisenberg E. Lichenoid dysplasia: a distinct histopathologic entity. Oral Surg 1985;60:308-15.

9 Kramer IRH, Lucus RB, El-Labban NG, Lister L. A computeraided study on the tissue changes in oral keratoses and lichen planus, and an analysis of case grouping by subjective and objective criteria. Br J Cancer 1970;24:407-26.

10 Pindborg JJ, Reibel J, Holmstrup P. Subjectivity in evaluating epithelial dysplasia, carcinoma in situ and initial carcinoma. J Oral Pathol 1985;14:698-708.

11 Axell T, Holmstrup P, Kramer IRH, Pindborg JJ, Shear M. International seminar on oral leukoplakia and associated lesions related to tobacco habits. Community Dent Oral Epidemiol 1984;12:145-54.

12 Shabana AHM, El-Labban NG, Lee KW. Morphometric analysis of the basal cell layer in oral premalignant white lesions and squamous cell carcinoma. J Clin Pathol 1987;40:454-8.

13 Shabana AHM. Immunohistochemical and quantitative morphological studies of the oral epithelium in premalignant white lesions and squamous cell carcinoma. [PhD Thesis] London University, 1986.

14 Schrek R. Ultrastructure of blood lymphocytes from chronic lymphocytic and lymphosarcoma cell leukemia. JNCI 1972; 48:51-64.

15 Chalkley HW. Method for quantitative morphologic analysis of tissues. JNCI 1943;4:47-53.

16 Steer MW. Understanding cell structure. Cambridge: Cambridge University Press, 1981.

17 Cohen L, Holliday M. Statistics for social scientists. An introductory text with computer programs in basic. London: Harper and Row, 1982.

18 Jagoe R, Sowter C, Slavin G. Shape and texture analysis of liver cell nuclei in hepatomas by computer-aided microscopy. J Clin Pathol 1984;37:755-62.

19 Tarin D. Further electron microscopic studies on the mechanism of carcinogenesis: the specificity of changes in carcinogentreated mouse skin. Int J Cancer 1968;3:734-42.

20 Craig GT, Franklin CD. The effect of turpentine on hamster cheek pouch mucosa: a model of epithelial hyperplasia and hyperkeratosis. J Oral Pathol 1977;6:268-77.

21 Eveson JW, MacDonald DG. Quantitative histological changes during early experimental carcinogenesis in the hamster cheek pouch. Br J Dermatol 1978;98:639-44.

22 Eveson JW, MacDonald DG. Hamster tongue carcinogenesis. II Quantitative morphologic aspects of preneoplastic epithelium. J Oral Pathol 1981;10:332-41.

23 Mackenzie IC, Miles AEW. The effect of chronic frictional stimulation on hamster cheek pouch epithelium. Arch Oral Biol 1973;18:1341-9.

24 Potten CS, Allen TD. The fine structure and cell kinetic of mouse epidermis after wounding. J Cell Sci 1975;17:413-47.

25 Andersen $L$. Quantitative analysis of epithelial changes during wound healing in palatal mucosa of guinea pigs. Cell Tissue Res 1978;193:231-46. 
26 Pinkus H. Examination of the epidermis by the strip method. Biometric data on regeneration of the human epidermis. J Invest Dermatol 1952;19:431-47.

27 Chase HB, Montagna W, Malone JD. Changes in the skin in relation to the hair growth cycle. Anat $\operatorname{Rec} 1953$;116:75-81.

28 Boon ME, Rietveld WJ. Time of ovulation reflected in nuclear and cytoplasmic size of vaginal and buccal epithelial cells. Obstet Gynecol 1980;8:778-9.

29 Schroeder HE, Preisi E, Marinello CP. Size of corneocytes and non-keratinized superficial cells of the human oral mucosa at different ages. J Biol Buccale 1985;13:237-49.

30 Sulzberger MB, Whitten VH. Lichen planus of the lip mimicking cancer or precancer. Comm Med 1959;23:663-5.

31 Cahn LR. The early detection of cancer of the mouth. Br Dent $J$ 1961;111:285-90.

32 Egglestone DJ. Lichen planus or leukoplakia: a case of clinical interest. Oral Surg 1970;29:849-54.

33 Reisman RJ, Schwartz AE, Friedman EW, Gerry RG. The malignant potential of oral lichen planus: diagnostic pitfalls. Oral Surg 1974;38:227-32.

34 Haidar Z, Lamm PKP. Leukoplakia and lichen planus: report of two cases. Br Dent J 1981;151:374-6.

35 Krutchkoff DJ, Cutler L, Laskowski S. Oral lichen planus: the evidence regarding potential malignant transformation. J Oral Pathol 1978;7:1-7.

Requests for reprints to: Dr A H M Shabana, Laboratoire Biologie-Odontologie, Tour 43-44 5ème étage, Université Paris 7, 2 place Jussieu, F-75251 Paris, Cedex 05, France. 